\title{
[Sn9HgSn9]6-: An Intermetalloid Zintl Ion with Two Sn9 Connected by Heteroatom
}

\begin{tabular}{|c|c|}
\hline Journal: & Zeitschrift für Anorganische und Allgemeine Chemie \\
\hline Manuscript ID: & zaac. 201000103.R1 \\
\hline Wiley - Manuscript type: & Communication \\
\hline $\begin{array}{r}\text { Date Submitted by the } \\
\text { Author: }\end{array}$ & \\
\hline Complete List of Authors: & $\begin{array}{l}\text { Faessler, Thomas; Technische Universitaet Muenchen, Department } \\
\text { Chemie } \\
\text { Yong, Li; University of Tennessee, Department of Chemistry } \\
\text { Boeddinghaus, Bele; Technische Universität München, Department } \\
\text { Chemie }\end{array}$ \\
\hline Keywords: & Zintl ion, Tin, Mercury, Cluster compound, Crystal structure \\
\hline
\end{tabular}

\section{S ScholaroNE \\ Manuscript Central}




\author{
Li Yong $^{[a]}$, M. Bele Boeddinghaus ${ }^{[b]}$ and Thomas F. Fässler ${ }^{*[b]}$
}

[a] Dr. L. Yong, Current address: Department of Chemistry, University of Tennessee, Knoxville, Tennessee 37996-1600

[b] Prof. T. F. Fässler, Dipl. Chem. M. Bele Boeddinghaus Technische Universität München, Department Chemie Lichtenbergstraße 4, D-85747 Garching, Germany Fax: (049)-8928913161 E-mail: Thomas.Faessler@1rz.tu-muenchen.de $[* *]$ This work was supported by DFG.

Dedicated to Prof. Kniep on the Occasion of his $65^{\text {th }}$ Birthday

Keywords: Zintl ion; Tin; Mercury; Cluster compound; Crystal structure

\begin{abstract}
The title compound $[\mathrm{K}([2,2,2] \mathrm{crypt})]_{12}\left[\mathrm{Sn}_{9}\right]_{2}\left[\mathrm{Sn}_{9} \mathrm{HgSn}_{9}\right]$ has been obtained by reaction of elemental mercury with the binary phase $\mathrm{K}_{4} \mathrm{Sn}_{9}$ in ethylenediamine after addition of [2,2,2]crypt and layering with toluene. The X-ray single crystal analysis shows that the compound consists of two isolated $\mathrm{Sn}_{9}$ clusters and two $\mathrm{Sn}_{9}$ clusters connected by a mercury atom.
\end{abstract}




\section{Introduction}

Homoatomic-element polyhedra of the type $\mathrm{E}_{\mathrm{n}}{ }^{\mathrm{x}-}(\mathrm{E}=$ Group 14 element $)$ are promising candidates for the formation of ligand-free intermetalloid clusters ${ }^{[1]}$. The introduction of a second metal to the polyhedral framework might occur via complexation to an organometallic metal fragment such as $\left[\operatorname{Ir}\left(\eta^{4}-\mathrm{E}_{9}\right)(\mathrm{cod})\right]^{3-}(\mathrm{E}=\mathrm{Sn}, \mathrm{Pb})^{[2]},\left[\mathrm{Ge}_{9}-\mathrm{Ni}(\mathrm{CO})\right]^{3-}{ }^{[3]},\left[\mathrm{Cu}\left(\eta^{4}-\mathrm{Ge}_{9}\right)\left(\mathrm{P}^{\mathrm{i}} \mathrm{Pr}\right)_{3}\right]^{3-}{ }^{[4]}$, $\left[\mathrm{Zn}\left(\eta^{4}-\mathrm{E}_{9}\right)(\mathrm{R})\right]^{3-}\left(\mathrm{R}=\mathrm{C}_{6} \mathrm{H}_{5}, \mathrm{E}=\mathrm{Si}-\mathrm{Pb}^{[5]} ; \mathrm{R}={ }^{\mathrm{i}} \mathrm{Pr}, \mathrm{Mes}, \mathrm{E}=\mathrm{Ge}-\mathrm{Pb}^{[6]}\right),\left[\mathrm{Pd}\left(\eta^{4}-\mathrm{Ge}_{9}\right)\left(\mathrm{PPh}_{3}\right)\right]^{3-[7]}$, $\left[\mathrm{Cd}\left(\eta^{4}-\mathrm{E}_{9}\right)\left(\mathrm{C}_{6} \mathrm{H}_{5}\right)\right]^{3-}$ and $\left[\mathrm{Cd}\left(\eta^{4}-\mathrm{Sn}_{9}\right)\left(\mathrm{Sn}^{\mathrm{n}} \mathrm{Bu}_{3}\right)\right]^{3-[8]}$. The first examples of ligand free heteroatomic clusters was reported in form of a linear polymeric chain ${ }_{\infty}^{1}\left[\mathrm{HgGe}_{9}\right]^{2-}$ in which $\mathrm{Hg}$ atoms act as bridges between the $\mathrm{Ge}_{9}$ clusters ${ }^{[9]}$. Recently an oligomeric extract $\left[\mathrm{Hg}_{3}\left(\mathrm{Ge}_{9}\right)_{4}\right]^{10-}$ of the polymeric chain has also been reported ${ }^{[10]}$. Up to now many attempts to prepare heteroatomic linked $\mathrm{Sn}_{9}$ clusters have been unsuccessful in solution chemistry. A comparable attempt using Te atoms to link $\mathrm{Sn}_{9}$ leads to the breakdown of the cluster and formation of the heteroatomic ions $\left[\mathrm{Te}_{2} \mathrm{Sn}\left(\mu_{2}-\mathrm{Te}\right)_{2} \mathrm{SnTe}_{2}\right]^{4-}$ and $\left[\mathrm{Sn}\left(\mu_{2}-\mathrm{Te}\right)_{3} \mathrm{Sn}\right]^{2-[11]}$. It is worth noting that the homoatomic oligomers of $\mathrm{Sn}_{9}$ are also unknown though their corresponding $\mathrm{Ge}_{9}$ have been reported successively in the last several years ${ }^{[12]}$.

Our reinvestigation of the reaction of elementary $\mathrm{Hg}$ with $\mathrm{Sn}_{9}$ clusters in analogy to the $\mathrm{Ge}_{9}$ clusters $^{[9]}$ by careful use of slow diffusion techniques resulted in the growth of black column crystals containing two isolated $\mathrm{Sn}_{9}$ cluster ions and one $\left[\mathrm{Sn}_{9} \mathrm{HgSn}_{9}\right]^{6-}$ ion (Figure 1).

\section{Results and Discussion}

Single X-ray diffraction measurement ${ }^{[13]}$ reveals the formulae $[\mathrm{K}([2,2,2] \mathrm{crypt})]_{12}\left[\mathrm{Sn}_{9}\right]_{2}\left[\mathrm{Sn}_{9} \mathrm{HgSn}_{9}\right]$ (Figure 1), which consists of two isolated $\mathrm{Sn}_{9}$ clusters and two $\mathrm{Sn}_{9}$ clusters being connected by a mercury atom. The twelve $[\mathrm{K}([2,2,2] \mathrm{crypt})]^{+}$cations do not show any coordination to the $\mathrm{Sn}_{9}$ cluster anions.

For nine-atom clusters, the ratio $h / e$ of prism heights $h$ (A: Sn19-Sn21, Sn25-Sn26, Sn23-Sn24; B: $\mathrm{Sn} 28-\mathrm{Sn} 30, \mathrm{Sn} 32-\mathrm{Sn} 33, \mathrm{Sn} 34-\mathrm{Sn} 35)$ to prism edge $e$ of a $D_{3 h}$ symmetric tricapped trigonal prismatic structure, and the ratio of the two diagonals $d$ (A: Sn19-Sn21, Sn20-Sn22, B: Sn28$\mathrm{Sn} 30, \mathrm{Sn} 29-\mathrm{Sn} 31)$ in the open rectangular face of the $C_{4 v}$ symmetric mono-capped square- 
antiprism provides the best correlation of configuration with electron count ${ }^{[14,15]}$. The two isolated nine atom clusters with virtual $C_{2 v}$ symmetry (Figure 2) adapt different shapes intermediate between the $D_{3 h}$ structure (closo type) and the mono-capped quadratic antiprismatic structure (nido type). In both anions one of the three heights of the underlying trigonal prism is elongated $\left(\mathbf{A}: \mathrm{d}_{\mathrm{Sn} 19-\mathrm{Sn} 21}=3.4546(9) \AA\right.$ versus $3.2321(9) \AA, 3.2162(9) \AA ; \quad \mathbf{B}: \mathrm{d}_{\mathrm{Sn} 28-\operatorname{Sn} 30}=$

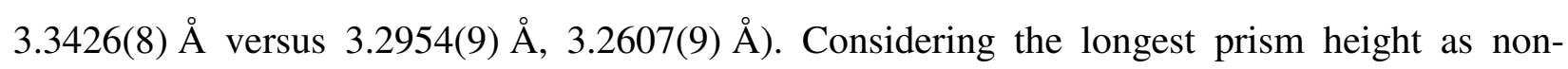
bonding, the ratios of the diagonals of the distorted square are 1.37 and 1.44 for the clusters $\mathbf{A}$ and $\mathbf{B}$, respectively, indicating a strong distortion from $C_{4 v}$ symmetry with expected values of 1.00. With average values of 3.300 and 3.301 for $h$ and 3.074 and 3.066 for $e$, the h/e ratio of the clusters $\mathbf{A}$ and $\mathbf{B}$ is for both 1.07. Thus, the ratios are quite similar with those of $\mathrm{Sn}_{9}{ }^{3-}$ ions in $[\mathrm{K}([2.2 .2] \mathrm{crypt})]_{3} \mathrm{Sn}_{9} \cdot 1.5 \mathrm{en}^{[14]}$ and of $[\mathrm{K}([2.2 .2] \mathrm{crypt})]_{3} \mathrm{Sn}_{9} \bullet 0.5 \mathrm{en}^{[16]}$ having values of 1.08 and 1.07 , respectively.

In the $\left[\mathrm{Sn}_{9} \mathrm{HgSn}_{9}\right]^{6-}$ anion, two $\mathrm{Sn}_{9}$ clusters $\mathbf{C}$ and $\mathbf{D}$ are connected by the $\mathrm{Hg}$ atom (Figure 3). The anion has nearly a center of inversion at the $\mathrm{Hg}$ atom position and the $\mathrm{Sn}_{9}$ clusters adapt to distorted tricapped trigonal prisms with approximately $C_{2 v}$ symmetry. The $\mathrm{Sn}-\mathrm{Sn}$ bond lengths range from 2.9134(9) $\AA$ to 3.2889(9) $\AA$ and are in accordance with those known in other $\mathrm{Sn}_{9}{ }^{[17]}$ and $\mathrm{Sn}_{6}{ }^{[18]}$ clusters. In both $\mathrm{Sn}_{9}$ clusters one of the three heights of the underlying trigonal prism is shorter $\left(\mathrm{d}_{\mathrm{Sn} 5-\mathrm{Sn} 6}=3.2652(9) \AA\right.$ versus 3.4184(9) $\AA$, 3.5636(9) $\AA$ for $\mathbf{C} ; \mathrm{d}_{\mathrm{Sn} 16-\mathrm{Sn} 17}=3.2889(9) \AA$ versus 3.5496(9) $\AA$, 3.4413(9) $\AA$ ) in D). With average values of 3.416 and 3.427 for $h$ and 3.051 and 3.045 for $e$, the $h / e$ ratio of the clusters is 1.12 and 1.13. The elongation of the three prismatic edges Sn1-Sn3, Sn5-Sn6 and Sn7-Sn8 and Sn10-Sn12, Sn14-Sn15 and Sn16-Sn17 in these Sn clusters account also for the additional contacts to $\mathrm{Hg}$ atoms. The $\mathrm{Sn}_{9}$ clusters coordinate via two triangular faces to the $\mathrm{Hg}$ atom, each with two shorter $\left(\mathrm{d}_{\mathrm{Sn1}-\mathrm{Hg}}=3.0438(8) \AA, \mathrm{d}_{\mathrm{Sn} 8-\mathrm{Hg}}=\right.$ $3.0834(7) \AA$ in $\mathbf{C} ; d_{\mathrm{Sn} 10-\mathrm{Hg}}=3.0114(7) \AA, \mathrm{d}_{\mathrm{Sn} 14-\mathrm{Hg}}=3.1530(8) \AA$ in $\left.\mathbf{D}\right)$ and one longer contact $\left(\mathrm{d}_{\mathrm{Hg}-\mathrm{Sn} 5}=3.4559(7) \AA\right.$ in $\mathbf{C} ; \mathrm{d}_{\mathrm{Hg}-\mathrm{Sn} 17}=3.4132(7) \AA$ in $\left.\mathbf{D}\right)$. These bond lengths are somewhat longer than the sum of their respective covalent radii $(2.84 \AA)^{[19]}$ reflecting the high coordination number of the $\mathrm{Hg}$ atom. Due to the interaction with the $\mathrm{Hg}$ atom, the triangular face made of atoms $\mathrm{Sn} 1, \mathrm{Sn} 5, \mathrm{Sn} 8$ is enlarged $\left(\mathrm{d}_{\mathrm{Sn} 1-\mathrm{Sn} 8}=3.0429(8), \mathrm{d}_{\mathrm{Sn} 1-\mathrm{Sn} 5}=3.1116(8), \mathrm{d}_{\mathrm{Sn} 5-\mathrm{Sn} 8}=3.0794(8)\right)$ with respect to the opposite triangular face made of $\operatorname{Sn} 3, \operatorname{Sn} 6, \operatorname{Sn} 7\left(\mathrm{~d}_{\mathrm{Sn} 3-\mathrm{Sn} 7}=2.9608(8), \mathrm{d}_{\mathrm{Sn} 3-\mathrm{Sn} 6}=\right.$ 3.0750(9), $\left.\mathrm{d}_{\mathrm{Sn6}-\mathrm{Sn} 7}=3.0350(8)\right)$. The $\mathrm{Sn}$ atoms with the weakest interaction with $\mathrm{Hg}(\mathrm{Hg}-\mathrm{Sn} 5$, Hg-Sn17) form the shortest prismatic edge $\left(d_{\text {Sn5-Sn6 }}=3.2652(9) \AA, d_{\text {Sn16-Sn17 }}=3.2889(9) \AA\right)$. The $\mathrm{Hg}$ atom is coordinated by the four nearest $\mathrm{Sn}$ atoms $\mathrm{Sn} 1, \mathrm{Sn} 8, \mathrm{Sn} 10$ and $\mathrm{Sn} 14$ in a rectangular- 
planar fashion with the mercury atom lying in the plane of those tin atoms. The bond angles of Sn1-Hg-Sn10 and Sn8-Hg-Sn14 are $176.4^{\circ}$ and $176.6^{\circ}$ respectively and hence close to $180^{\circ}$. A rectangular or square-planar coordination is rather uncommon but has been observed for $\mathrm{Hg}$ (II) complexes. ${ }^{[20]}$ In $\left[\mathrm{Sn}_{9} \mathrm{HgSn}_{9}\right]^{6-}$ to further and longer $\mathrm{Hg}$-Sn contacts occur resulting in a strongly distorted trigonal anti-prismatic coordination polyhedra. with $\mathrm{Sn} 5-\mathrm{Hg}-\mathrm{Sn} 17$ bond angle of $174.9^{\circ}{ }^{[21]}$.

Since the product contains $[\mathrm{K}([2,2,2] \mathrm{crypt})]_{6}\left[\mathrm{Sn}_{9}\right]_{2} \cdot 1.5 \mathrm{en} \cdot 0.5$ tol ${ }^{[22]}$ as paramagnetic impurity the spin state of the title compound could not be determined unambiguously and the charge allocation is not obvious. Due to their similarity to other known $\left[\mathrm{Sn}_{9}\right]^{3-}$ ions, we assume the two isolated clusters carry a charge of -3 as well. That postulates a $\left[\mathrm{Sn}_{9} \mathrm{HgSn}_{9}\right]^{6-}$ anion. In analogy to ${ }_{\infty}^{1}\left[\mathrm{HgGe}_{9}\right]^{2-}$ formal oxidation states for $\mathrm{Hg}$ of +2 and 0 according to $\left(\left[\mathrm{Sn}_{9}\right]^{4-}\right) \mathrm{Hg}^{2+}\left(\left[\mathrm{Sn}_{9}\right]^{4-}\right)$ and $\left(\left[\mathrm{Sn}_{9}\right]^{3-}\right)-\mathrm{Hg}-\left(\left[\mathrm{Sn}_{9}\right]^{3-}\right)$ can be assigned.

In the polymers ${ }_{\infty}^{1}\left[\mathrm{HgGe}_{9}\right]^{2-[9]}$ the $\mathrm{Hg}$ atoms is linearly coordinated to one Ge atom of each of the two neighboring Ge9 clusters. In the oligomer $\left[\mathrm{Hg}_{3}\left(\mathrm{Ge}_{9}\right)_{4}\right]^{10-[10]}$ the same holds for the central $\mathrm{Hg}$ atom, whereas the coordination to the terminal $\mathrm{Ge}_{9}$ clusters is of $\eta^{2}$ fashion resulting in three nearest $\mathrm{Hg}-\mathrm{Ge}$ contacts.

\section{Conclusion}

Our investigations showed the preparation of heteroatomic linked $\mathrm{Sn}_{9}$ clusters in solution chemistry is possible, analogous to those of germanium. The rectangular planar coordination of $\mathrm{Hg}$ by four $\mathrm{Sn}$ atoms hints for a $\mathrm{Hg}(\mathrm{II})$ compound and thus differs the coordination of the $\mathrm{Hg}$ atom from the related compounds containing $\mathrm{Ge}_{9} \mathrm{HgGe}_{9}$ building blocks.

\section{Experimental Section:}

The synthesis of compound $\mathbf{1}$ was carried out under argon atmosphere using a glove-box or Schlenk line. Toluene (Merck) and ethylenediamine (Merck) were dried over $\mathrm{CaH}_{2}$ (Fluka), freshly distilled and degassed. The binary phase of the formal composition " $\mathrm{K}_{4} \mathrm{Sn}_{9}$ " was prepared by high-temperature reaction $\left(650{ }^{\circ} \mathrm{C}\right)$ from the elements $\mathrm{K}$ and $\mathrm{Sn}$ in the ratio of 4:9. 
$\mathrm{K}_{4} \mathrm{Sn}_{9}$ (200 $\left.\mathrm{mg}, 0.164 \mathrm{mmol}\right)$ and [2,2,2]crypt (246 $\mathrm{mg}, 0.65 \mathrm{mmol}$ ) were dissolved in ethylenediamine (ca. $2 \mathrm{ml}$ ) in a $25 \mathrm{ml}$ Schlenk tube and stirred for $5 \mathrm{~min}$ to yield a dark red solution. Then $\mathrm{Hg}$ (200mg, 1 $\mathrm{mmol}$ ) was added dropwise at room temperature. The resulting mixture was stirred for another 2 hours at room temperature to yield a reddish-brown solution. Afterwards the reaction was treated for $20 \mathrm{~min}$. in an ultrasonic bath, and then filtered. The filtrate was layered with toluene $(2 \mathrm{~mL})$. After 48 hours, dark column crystals contains $[\mathrm{K}([2,2,2] \mathrm{crypt})]_{12}\left[\mathrm{Sn}_{9}\right]_{2}\left[\mathrm{Sn}_{9} \mathrm{HgSn}_{9}\right]$ precipitated with the yield of $50 \mathrm{mg}$, (ca. $35 \%$ with respect to $\mathrm{K}_{4} \mathrm{Sn}_{9}$ ). The EDX analysis of crystal shows the existence of elements $\mathrm{K}, \mathrm{Hg}$ and $\mathrm{Sn}$ with approximately the expected ratio of these elements of 12:1:36. $[\mathrm{K}([2,2,2] \mathrm{crypt})]_{6}\left[\mathrm{Sn}_{9}\right]_{2} \cdot 1.5 \mathrm{en} \cdot 0.5$ tol $^{[22]}$ was obtained as byproduct as shown by lattice parameter determination of single crystals.

\section{Acknowledgement}

We thank Dr. Bernhard Wahl for crystallographic advise and Dr. Michael J. Evans for reading the manuscript.

\section{References and notes}

[1] a) T. F. Fässler, S. D. Hoffmann, Angew. Chem. Int. Ed. 2004, 43, 6242; Angew. Chem. 2004, 116, 6400; b) S. C. Sevov, J. M. Goicoechea, Organometallics 2006, 25, 5678; c) S. Scharfe, T. F. Fässler, Phil. Trans. R. Soc. A 2010, 368, 1265.

[2] a) J.-Q. Wang, S. Stegmaier, B. Wahl, T. F. Fässler, Chem. Eur. J. 2010, 16, 1793; b) D. O. Downing, P. Zavalij, B. W. Eichhorn, Eur. J. Inorg. Chem. 2010, 6, 890.

[3] J. M. Goicoechea, S. C. Sevov, J. Am. Chem. Soc. 2006, 128, 4155.

[4] S. Scharfe, T. F. Fässler, Eur. J. Inorg. Chem. 2010, in press, DOI: 10.1002/ejic.200901038.

[5] J. M. Goicoechea, S. C. Sevov, Organometallics 2006, 25, 4530.

[6] B. Zhou, M. S. Denning, C. Jones, J. M. Goicoechea, Dalton Trans. 2009, 1571.

[7] Z.-M. Sun, Y.-F. Zhao, J. Li, L.-S. Wang, Journal of Cluster Science 2009, 20, 601.

[8] B. Zhou, M. S. Denning, T. A. D. Chapman, J. M. Goicoechea, Inorg. Chem. 2009, 48, 2899.

[9] a) A. Nienhaus, R. Hauptmann, T. F. Fässler, Angew. Chem. Int. Ed. 2002, 41, 3213; b) M. B.

Boeddinghaus, S. D. Hoffmann, T. F. Fässler, Z. Anorg. Allg. Chem. 2007, 633, 2338.

[10] M. S. Denning, J. M. Goicoechea, Dalton Trans. 2008, 5882. 
[11] T. F. Fässler, U. Schütz, J. Organomet. Chem. 1997, 541, 269.

[12] a) L. Xu, S. C. Sevov, J. Am. Chem. Soc. 1999, 121, 9245; b) A. Ugrinov, S. C. Sevov, J. Am. Chem. Soc. 2002, 124, 10990; c) A. Ugrinov, S. C. Sevov, Inorg. Chem. 2003, 42, 5789; d) L. Yong, S. D. Hoffmann, T. F. Fässler, Z. Anorg. Allgem. Chem. 2004, 630, 1977; e) L. Yong, S. D. Hoffmann, T. F. Fässler, Z. Anorg. Allg. Chemie 2005, 631, 1149; f) R. Hauptmann, T. F. Fässler, Z. Anorg. Allg. Chem. 2003, 629, 2266; g) R. Hauptmann, T. F. Fässler, Z. Krist. NCS 2003, $218,461$.

[13] Crystal structure determination: Crystals were mounted in glass capillaries. Structure solution (SHELX-97 and refinement SHELXL-97) was carried out with direct methods and fullmatrix least-square methods based on $\mathrm{F}^{2}$ for non-hydrogen atoms with anisotropic displacement parameters, except for the atoms of five crypt molecules. Due to disorder their non-hydrogen atoms were splitted using JANA2006 (Petricek,V., Dusek,M. \& Palatinus,L.). The corresponding atoms were labeled with ' and were refined with equal isotropic displacement parameters. Due to disorder of the solvent molecules, their contribution to the structure factors were modeled using the SQUEEZE option in PLATON. All hydrogen atoms were calculated using a riding model. Crystal dimensions: 0.4 x 0.4 x $0.2 \mathrm{~mm}$. Lattice constants at $120 \mathrm{~K}: a=27.8452(1) \AA$, $b=28.3340(1) \AA, c=28.9569(2) \AA \alpha=68.4618(2)^{\circ}, \beta=69.7966(2)^{\circ}, \gamma=61.3741(3)^{\circ}, V=17870.26(7)$ $\AA^{3}$; space group P-1 (No. 2); $\mathrm{Z}=2, \rho_{\text {calcd }}=1.833 \mathrm{~g} / \mathrm{cm}, \mu=3.097 \mathrm{~mm}^{-1}$; Data collection: Nonius Kappa CCD device at the window of a rotating anode X-ray generator; $\mathrm{Mo}_{\mathrm{k} \alpha}$ radiation, $2 \theta_{\max }=46.49 ; 190950$ total reflections, 50908 were independent reflections; completeness to $\theta$ $99.2 \%$; multi-scan absorption correction. $\left(\mathrm{R}_{\mathrm{int}}=0.086\right), \mathrm{R}_{1}=0.053$, and $\mathrm{wR}_{2}=0.090$ with $\mathrm{F}^{2}>2$ $\theta\left(F^{2}\right), R_{1}=0.095$ and $w R=0.102$ for all data, respectively. CCDC-767025 contains the supplementary crystallographic data for this paper. These data can be obtained free of charge via www.ccdc.cam.ac.uk/conts/retrieving.html (or from the Cambridge Crystallographic Data Centre, 12, Union Road, Cambridge CB21EZ, UK; fax: (+44) 1223-336-033; or deposit@ccdc.cam.ac.uk).

[14] S. C. Critchlow, J. D. Corbett, J. Am. Chem. Soc. 1983, 105, 5715.

[15] a) T. F. Fässler, M. Hunziker, Inorg. Chem. 1994, 33, 5380; b) T. F. Fässler, R. Hauptmann, J. Chem. Soc., Dalton Trans. 1999, 3339.

[16] L. Yong, S .D. Hoffmann, T. F. Fässler, Z. Kristallogr. NCS 2005, 220, 49.

[17] a) J. D. Corbett, P. A. Edwards, J. Am. Chem. Soc. 1977, 99, 3313; b) T. F. Fässler, R. Hauptmann, Angew. Chem. Int. Ed. 1999, 38, 543; c) B. Kesanli, J. Fettinger, B. Eichhorn, Chem. 
Eur. J. 2001, 7, 5277; d) B. Kesanli, J. Fettinger, D. R. Gardner, B. Eichhorn, J. Am. Chem. Soc. 2002, 124, 4779; e) J. Campbell, H. P. A. Mercier, H. Franke, D. P. Santry, D. A. Dixon, G. J. Schrobilgen, Inorg. Chem. 2002, 41, 86.

[18] a) G. Renner, P. Kircher, G. Huttner, P. Rutsch, K. Heinze, Eur. J. Inorg. Chem. 2001, 973;

b) P. Kircher, G. Huttner, K. Heinze, G. Renner, Angew. Chem. Int. Ed. 1998, 37, 1664.

[19] $\mathrm{r}_{\mathrm{Hg}}=1.44 \AA$ A , $\mathrm{r}_{\mathrm{Sn}}=1.40 \AA$ А: J. Emsley, The Elements, 3rd ed., Oxford, 1998.

[20]a) R. Haid, R. Gutmann, G. Czermak, C. Langes, W. Oberhauser, H. Kopacka, K.-H.

Ongania, P. Brüggeller, Inorg. Chem. Commun. 2003, 6, 61; b) K. R. Flower, R. G. Pritchard, Acta Crystallogr., Sect. E: Struct. Rep. Online 2006, 62, 1467.

[21] Sn-Sn distances $[\AA ̊]$ in $\left[\mathrm{Sn}_{9} \mathrm{HgSn}_{9}\right]^{6-}$ anion: Sn10-Sn11 2.9308(9), Sn10-Sn13 2.937(1), Sn10-Sn14 3.0325(8), Sn10-Sn17 3.0675(9), Sn11-Sn14 2.9295(9), Sn10-Sn12 3.5496(9), Sn11Sn15 2.9717(8), Sn11-Sn12 2.994(1), Sn12-Sn13 2.960(1), Sn12-Sn15 2.9713(8), Sn12-Sn16 3.0455(9), Sn13-Sn17 2.9412(9), Sn13-Sn16 2.9534(9), Sn14-Sn18 2.9384(9), Sn14-Sn17 3.1176(9), Sn14-Sn15 3.4413(9), Sn15-Sn18 2.9565(9), Sn15-Sn16 3.0324(9), Sn16-Sn18 2.9510(9), Sn16-Sn17 3.2889(9), Sn17-Sn18 2.9545(8), Sn1-Sn2 2.9236(9), Sn1-Sn4 2.9414(9), Sn1-Sn8 3.0429(8), Sn1-Sn5 3.1116(8), Sn1-Sn3 3.4184(9), Sn2-Sn5 2.9414(8), Sn2Sn6 2.9569(9), Sn2-Sn3 2.9646(9), Sn3-Sn7 2.9608(8), Sn3-Sn4 2.9895(9), Sn3-Sn6 3.0750(9), Sn4-Sn8 2.9134(9), Sn4-Sn7 2.9649(8), Sn5-Sn9 2.9568(8), Sn5-Sn8 3.0794(8), Sn5-Sn6 3.2652(9), Sn6-Sn9 2.9633(8), Sn6-Sn7 3.0350(8), Sn7-Sn9 2.9747(9), Sn7-Sn8 3.5636(9), Sn8Sn9 2.9389(8); Sn-Hg-Sn- angles [ [ ${ }^{\circ}$ : Sn10-Hg-Sn14 58.88(2), Sn10-Hg-Sn17 56.63(2), Sn14Hg-Sn17 56.52(2), Sn1-Hg-Sn8 59.55(2), Sn1-Hg-Sn5 56.78(2), Sn5-Hg-Sn8 55.84(2), Sn1-HgSn10 176.39(2), Sn8-Hg-Sn14 176.55(2), Sn5-Hg-Sn17 174.91(2) [22] T. F. Fässler, M. Hunziker, Z. Anorg. Allg. Chem. 1992, 622, 837. 


\section{Figure Captions}

Figure 1. The isolated $\left[\mathrm{Sn}_{9}\right]^{3-}$ ion and isolated $\left[\mathrm{Sn}_{9} \mathrm{HgSn}_{9}\right]^{6-}$ ion are represented in unit cell as polyhedra. The isolated $\left[\mathrm{Sn}_{9}\right]^{3-}$ ions and $\left[\mathrm{Sn}_{9} \mathrm{HgSn}_{9}\right]^{6-}$ ion are emphasized in Figure 2 and Figure 3, respectively.

Figure 2. View of the isolated $\mathrm{Sn}_{9}{ }^{3-}$ anions. (Thermal ellipsoids are shown at $50 \%$ probability level.)

Figure 3. Section of the molecular structure of $\left[\mathrm{Sn}_{9} \mathrm{HgSn}_{9}\right]^{6-}$ ion. (atomic displacement vectors are set at $50 \%$ probability). Some important interatomic distances ( $)$ and angles $\left[^{\circ}\right]$ : $\mathrm{d}_{\mathrm{Hg}-\mathrm{Sn} 1}=3.0438(8), \mathrm{d}_{\mathrm{Hg}-\mathrm{Sn} 8}=3.0834(7), \mathrm{d}_{\mathrm{Hg}-\mathrm{Sn} 10}=3.0114(7), \mathrm{d}_{\mathrm{Hg}-\mathrm{Sn} 14}=3.1530(8), \mathrm{Sn} 1-\mathrm{Hg}-\mathrm{Sn} 10$ $176.39(2)^{\circ}, \mathrm{Sn} 8-\mathrm{Hg}-\mathrm{Sn} 14176.55(2)^{\circ}$. For further distances and angles, see text and reference ${ }^{[21]}$. 


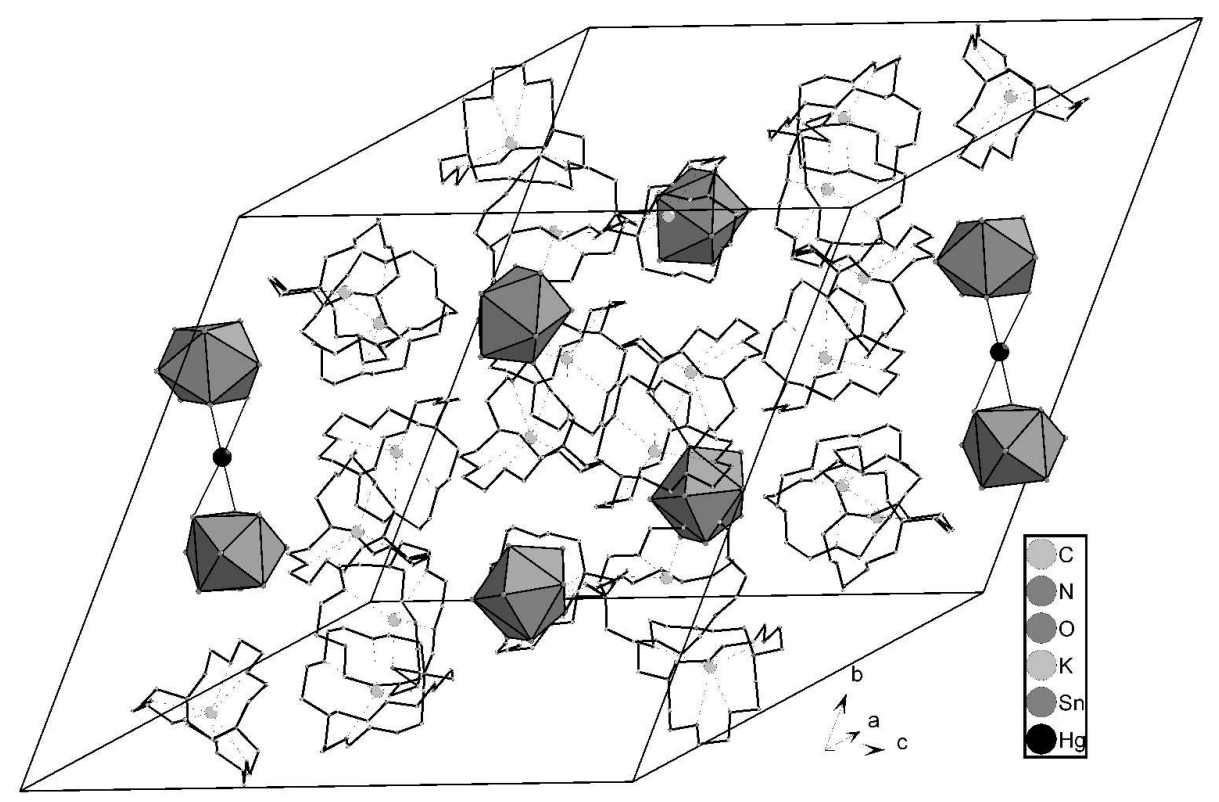

$1323 \times 991 \mathrm{~mm}(96 \times 96 \mathrm{DPI})$ 


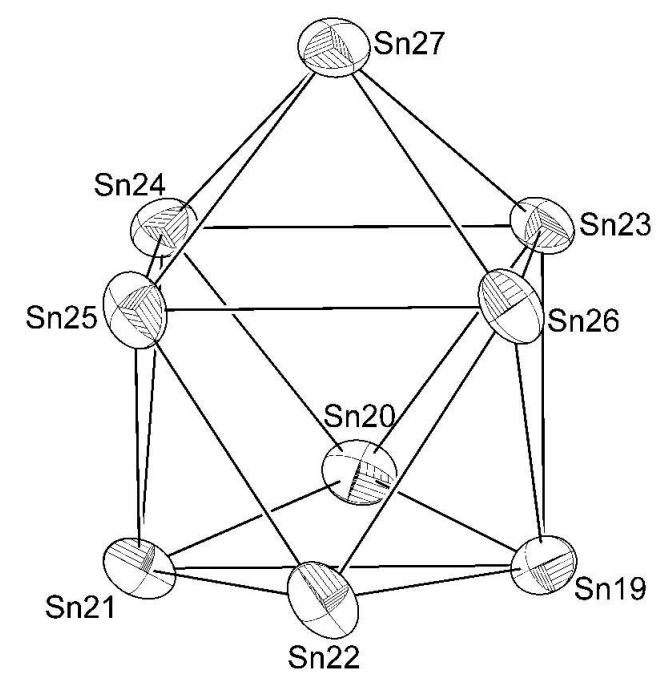

A

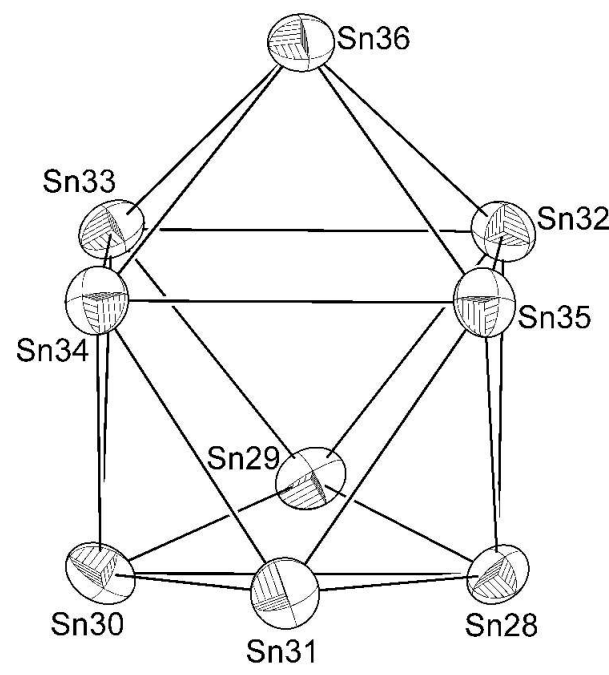

B

$275 \times 155 \mathrm{~mm}(600 \times 600 \mathrm{DPI})$ 


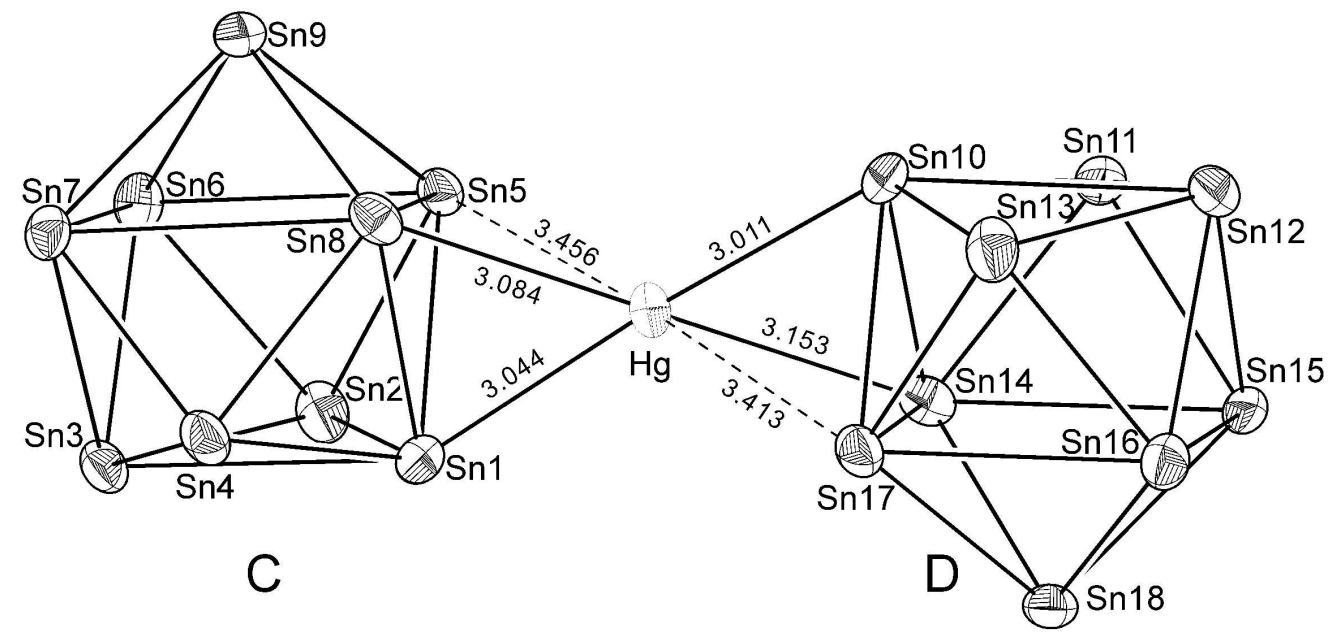

$194 \times 98 \mathrm{~mm}(600 \times 600 \mathrm{DPI})$ 